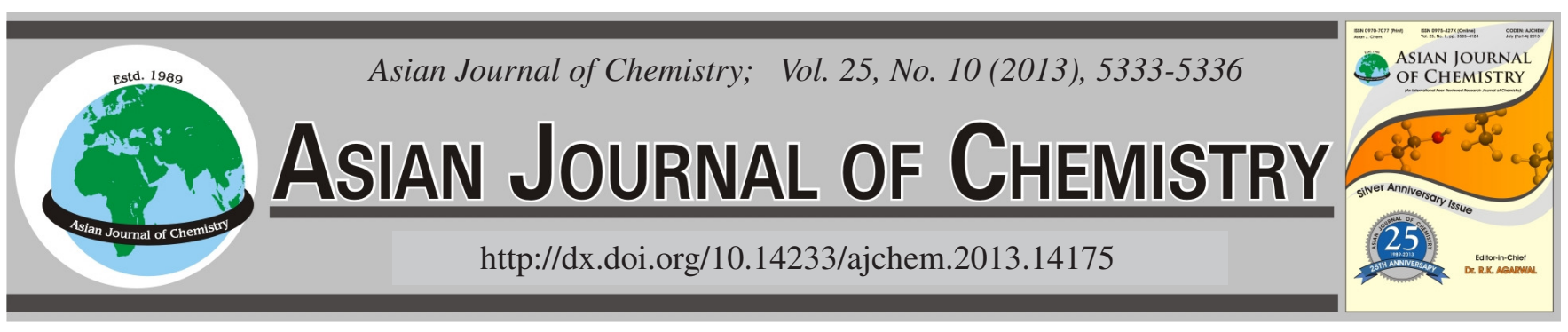

\title{
Microwave and Enzymatic Extraction of Orange Peel Pectin
}

\author{
XIAN-Chun Yu ${ }^{1, *}$ and De-Lin Sun ${ }^{2}$
}

${ }^{1}$ Key Laboratory of Chinese Herbal Medicine, Yueyang Vocational and Technical College, Yueyang 414000, Hunan Province, P.R. China ${ }^{2}$ College of Furniture and Art Design, Central South University of Forestry and Technology, Changsha 410004, Hunan Province, P.R. China

*Corresponding author: E-mail: sdlyxc@163.com

(Received: 7 June 2012;

Accepted: 3 April 2013)

AJC-13199

Pollution of inorganic acid can be reduced, pectin yield and purity can be increased by using microwave to process orange peels and then
adding complex enzyme to extract pectin. The infrared spectrum showed that orange pectin contained a relatively huge amount of
carbohydrates, but no protein. The extract technology was optimized by orthogonal experiments at $250 \mathrm{~W}$ microwave power, $50{ }^{\circ} \mathrm{C}$
microwave heating temperature, 10 min microwave processing time, $1 \mathrm{~h}$ single extraction time, buffer $\mathrm{pH} 4.5,50{ }^{\circ} \mathrm{C}$ enzyme extraction
temperature and $0.9 \%$ enzymatic dosage. Enzyme extraction was performed three times. The average yield in orange peel pectin was
$22.12 \%$, which was much higher than the pectin extraction yield using conventional water bath method under the same conditions.
Key Words: Orange peel pectin, Complex enzyme extraction, Microwave-assisted.

\section{INTRODUCTION}

Pectin is widely distributed in the cell walls of the roots, stems, leaves and fruits of higher plants. It is a polysaccharide polymer compound and is the main component of dietary fibers ${ }^{1}$, with good gelling and emulsion stabilities. Pectin is widely used in food, pharmaceutical and chemical industries and in other specific applications ${ }^{2}$. As fruit waste, orange peel has high levels of pectin and can be used as raw material for pectin extraction ${ }^{3}$.

Pectin extraction methods include acid extraction ethanol precipitation, ion exchange, acid extract salt precipitation, microbiological method, etc. Maria, Scabio and Sakai ${ }^{4-6}$ studied pectin extraction using inorganic acid hydrolysis method, whereas Willats et $a l^{7}$ discussed pectin extraction from apple pomace. The inorganic acid method is more widely used commercially ${ }^{8}$. However, inorganic acid extraction approach has multiple disadvantages, such as low yield, high energy consumption and environmental pollution ${ }^{9}$. Microwave heating can make the vacuole-containing cells expand and instantly break because of the rapid temperature increase, thus releasing intracellular substances ${ }^{10}$. This method is particularly suitable for the extraction of intracellular substances from plant cells. It exhibits large handling capacity, short processing time and good purity. Enzymatic extraction exhibits mild conditions, low energy consumption and no pollution ${ }^{11}$. It is a new biopharmaceutical plant extraction process.

Currently, no related reports are available on the application of microwave and enzymatic extraction on orange peel pectin. In this study, orange peel was used as raw material and orange peel pectin was extracted using a microwave and the compound enzyme approach to alleviate the deficiencies in traditional methods and to provide a new method for pectin production.

\section{EXPERIMENTAL}

Orange peel was purchased from the market. The main reagent and raw materials included acetic acid-sodium acetate buffer solution (Shanghai YANTUO Biotechnology Lit. Com); pectin acid and aspergillus enzyme (Beijing AOBOX Biotechnology Lit. Com); ethanol (analytically pure) and deionized water (from the laboratory).

The main equipment had an atmospheric pressure microwave-assisted synthesis reaction instrument (MAS-I, China), a vacuum drying oven (101A, China), a high-speed tissue grinder (JJ-2, China), a precise $\mathrm{pH}$ meter (pHS-828, China), an electric constant-temperature water bath (HH-2, China), a low-speed centrifuge (TDZ5-WS, China) and an infrared Fourier transform spectroscope (Varian 660, USA).

Methods: About $100 \mathrm{~g}$ orange peel powder with $0.4 \mathrm{~mm}$ particle size was mixed with a certain amount of acetic acidsodium acetate buffer. The mixture was placed in the atmospheric pressure microwave-assisted synthesis reaction instrument and then treated at a specified microwave power for a certain time.

When the mixture had cooled to room temperature, a certain amount of the compound enzyme (80\% pectin acid 
enzyme and $20 \%$ Aspergillus enzyme) was added. The mixture was placed in constant-temperature water bath at a specified temperature for certain time to be extracted 1 to 4 times. The extract was centrifuged at $4000 \mathrm{rpm}$ for $10 \mathrm{~min}$. The residue was separated, washed with distilled water, centrifuged again and then the supernatant was merged.

The supernatant was placed in $85^{\circ} \mathrm{C}$ water bath for $5 \mathrm{~min}$ to inactivate the enzyme. It was then cooled to room temperature, alcohol-precipitated with $95 \%$ ethanol and centrifuged at $4000 \mathrm{rpm}$ for $5 \mathrm{~min}$ to precipitate the pectin, which was then washed with $95 \%$ ethanol for 5 min to remove the pigment and free neutral sugar. Finally, the pectin was dried in a vacuum drying oven at $50{ }^{\circ} \mathrm{C}$ for $2 \mathrm{~h}$ and the yield was calculated according to eqn. 1 .

$$
\text { Pectin yield }=\left(\frac{\text { Pectin dry weight }}{\text { Raw material weight }}\right) \times 100 \%
$$

Contrast experiments were performed using conventional water bath extraction under similar process and conditions.

Measurement: The physiochemical indicators of pectin were measured according to GB 25533-2010. The infrared spectroscopy pectin was measured with a Fourier transform infrared spectrometer at a scanning range of 4000-500 $\mathrm{cm}^{-1}$.

Microwave treatment time and power: Fig. 1 shows the pectin yield diagram under different process times at microwave power settings of 100, 150, 200 and $250 \mathrm{~W}$. As shown in Fig. 1, microwave power exhibited large impact on pectin yield, which was relatively lower at low power. The pectin yield increased as the power was increased, After 10 min, however, the yield at 200 and $250 \mathrm{~W}$ became similar. Considering the production costs, $200 \mathrm{~W}$ power was used. In addition, Fig. 1 also shows that when the power was $200 \mathrm{~W}$ for $8 \mathrm{~min}$, the pectin yield slowly increased and the yield curve gradually became nearly flat over time. This result can be attributed to microwave heating, which can make vacuolecontaining cells expand and break to release intracellular materials in a short time. Early in the process, the intracellular releasing substances and the pectin yield increased over time. Further, the amount of intracellular releasing substances gradually decreased and the pectin yield had no significant increase. Thus, 8 min was chosen as the microwave processing time.

Microwave treatment temperature and buffer $\mathbf{p H}$ : Fig. 2 shows the pectin yield diagram at $30,40,50$ and $60{ }^{\circ} \mathrm{C}$ microwave temperature and different buffer $\mathrm{pHs}$. As shown in Fig. 2, the yield rose rapidly as the temperature increased, reached the maximum at $50{ }^{\circ} \mathrm{C}$ and then began to drop. This result may be due to the vacuolar cells, which had expanded and were instantly broken as the temperature rapidly increased and the intracellular material was released. However, the intracellularly released material had low stability. High temperature can induce the released materials to easily oxidize to form byproducts, which can affect the yield. Therefore, 50 ${ }^{\circ} \mathrm{C}$ was chosen as the microwave heating temperature. Fig. 2 also shows that high pectin yield was achieved at a processing temperature of $50^{\circ} \mathrm{C}$ buffer $\mathrm{pH}$ of 4 . The yield decreased when the $\mathrm{pH}$ value was over 4 , which may be due to the high enzymatic activity when $\mathrm{pH}$ was around 4 . Thus, a $\mathrm{pH}$ value of 4 was chosen for the buffer solution.

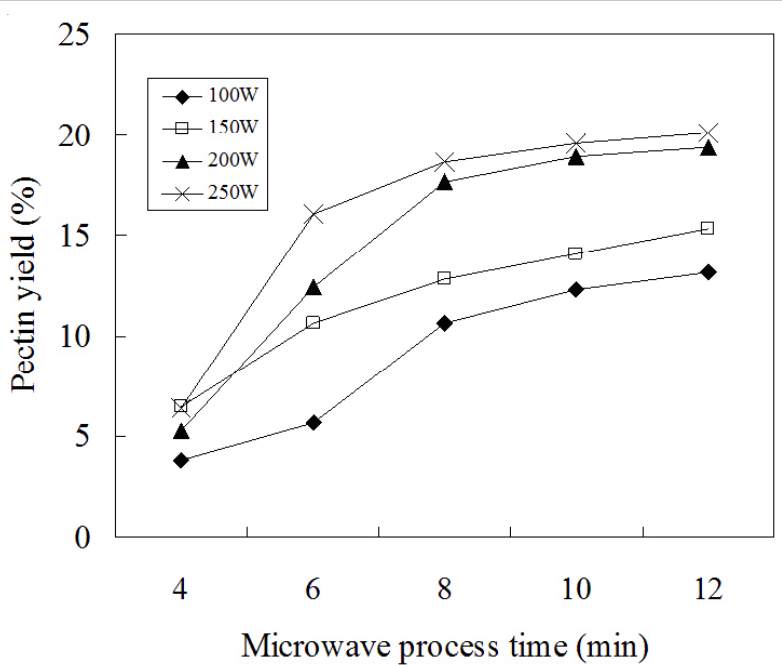

Fig. 1. Effect of microwave time and microwave power on pectin yield

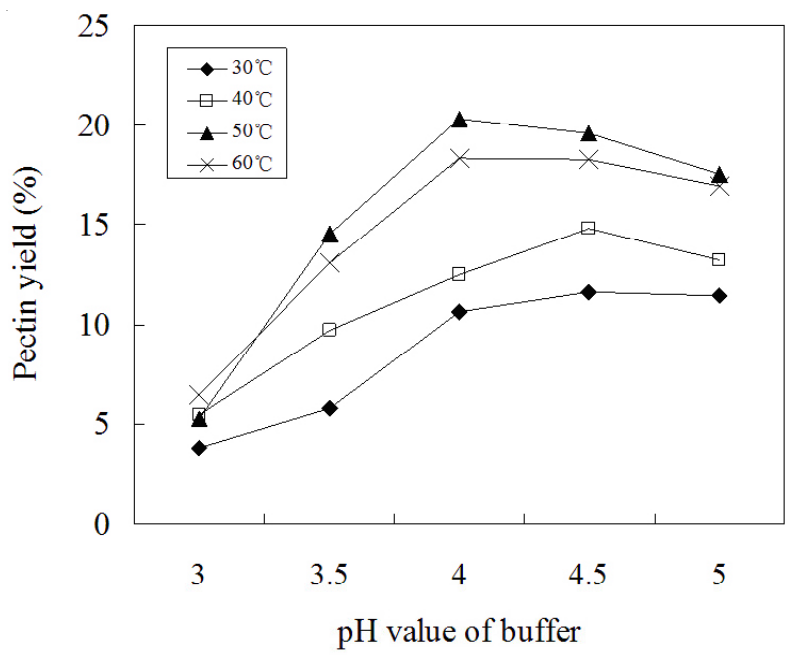

Fig. 2. Effect of $\mathrm{pH}$ value of buffer and microwave temperature on pectin yield

Enzymatic extraction temperature and dosage of enzymatic solution: Elevated temperature can increase the activation energy of the reaction system and thus enhance reaction rate ${ }^{12}$. However, high temperature will cause enzyme inactivation. Thus, a suitable extraction temperature is important. The impacts of different temperatures and enzyme dosages on pectin extraction yield are shown in Fig. 3. When the enzymatic extraction temperature was lower than $50{ }^{\circ} \mathrm{C}$, the pectin yield gradually increased as temperature increased, reaching a yield of $20.88 \%$ at $50{ }^{\circ} \mathrm{C}$. However, the yield decreased when the temperature continued to rise. This result may be due to the partial enzyme inactivation caused by high temperature. Thus, $50^{\circ} \mathrm{C}$ was chosen as the enzymatic extraction temperature in this study. At $50{ }^{\circ} \mathrm{C}$, when the enzymatic solution dosage was less than $0.7 \%$, the pectin extraction yield significantly increased as the enzymatic solution dosage increased. However, at a dosage above $0.7 \%$, the pectin yield slowly increased. This result can be explained by the enhanced substrate exposure and enzymatic reaction rate as the enzyme concentration increased. When the enzyme concentration became supersaturated, the excess enzyme hardly played a role $^{12}$, which led to the slow increase in pectin yield. 


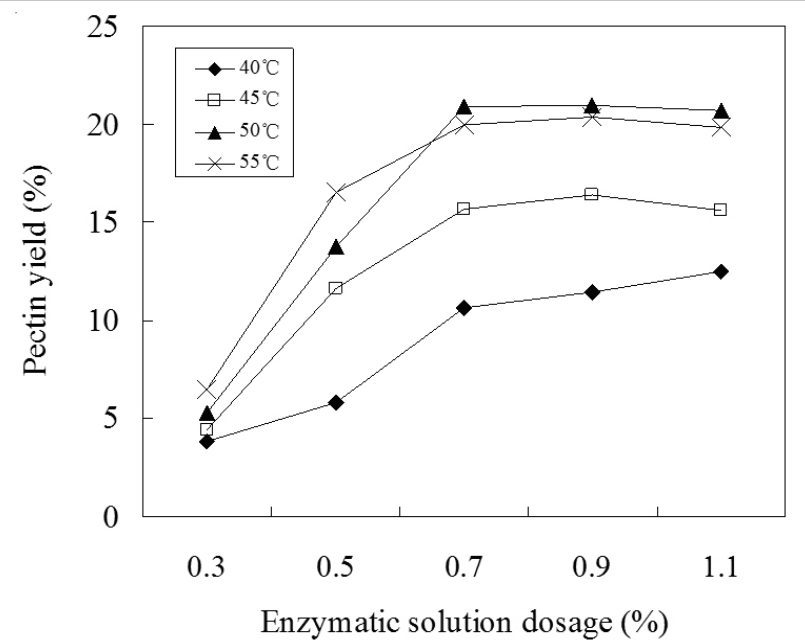

Fig. 3. Effects of enzyme dosages on the pectin yield

Impacts of single extraction time and multiple extraction times: Fig. 4 shows the impacts of multiple extraction times and single extraction time on pectin yield. The total pectin yield was augmented as the extraction time increased. The total pectin yield at four extraction times was slightly higher than that at three extraction times. Considering the production cost, three extraction times was considered appropriate. Fig. 4 also shows that at three extraction times, the total pectin yield gradually increased as the extraction time was extended. When the extraction time was over $55 \mathrm{~min}$, extended time led to reduced pectin yield, because extending the extraction time induces degradation of pectin molecular chains under the action of enzymes, eventually affecting pectin yield ${ }^{13}$. Thus, 55 min was chosen as the final single extraction time.

\section{RESULTS AND DISCUSSION}

Orthogonal test: Based on single-factor experiments, extraction was performed thrice with microwave power (A),

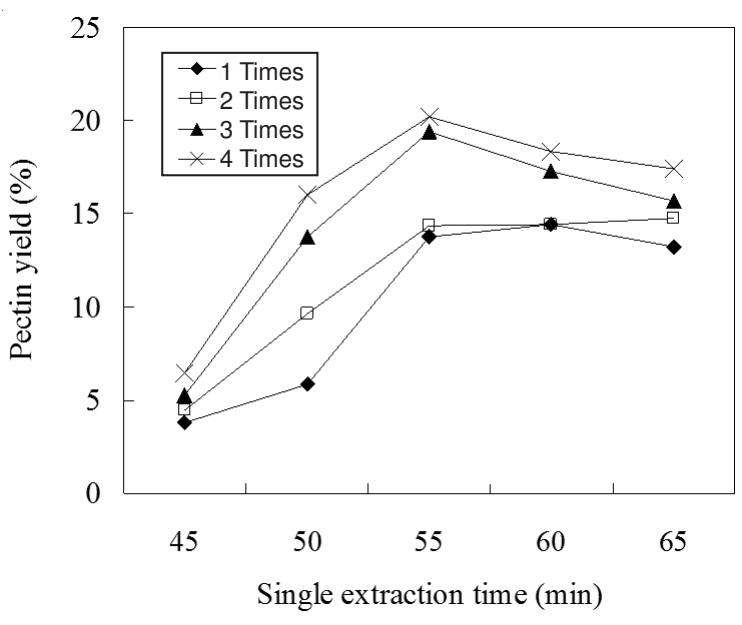

Fig. 4. Effects of enzyme extraction time on the pectin yield

microwave treatment temperature (B), microwave treatment time $(\mathrm{C})$, single extraction time (D), buffer solution $\mathrm{pH}(\mathrm{E})$, enzyme extraction temperature $(F)$ and enzymatic dosage $(G)$ as research objects. An orthogonal experiment was conducted using the $\mathrm{L}_{18}\left(3^{7}\right)$ table. The experimental results are shown in Table-1.

As shown in Table-1, the factors affect pectin yield in the following order: $A_{3}>B_{2}>F_{2}>C_{2}>D_{2}>G_{2}>E_{3}$ (i.e., the best process combination was $250 \mathrm{~W}$ microwave power, $50{ }^{\circ} \mathrm{C}$ microwave heating temperature, $10 \mathrm{~min}$ microwave processing time, $1 \mathrm{~h}$ single extraction time, 4.5 buffer $\mathrm{pH}, 50^{\circ} \mathrm{C}$ enzyme extraction temperature, $0.9 \%$ enzymatic dosage and three additional experiments using these optimal conditions). The average extraction yield in orange peel pectin was $22.12 \%$. Under similar conditions but without microwave-assisted heat, the pectin yield was only $14.41 \%$.

Infrared spectroscopy: The infrared spectrum of pectin is shown in Fig. 5. The broad band at $3600-3200 \mathrm{~cm}^{-1}$ was ascribed to the carbohydrate intramolecular or intermolecular $\mathrm{O}-\mathrm{H}$

TABLE-1

ORTHOGONAL EXPERIMENT RESULTS OF PECTIN EXTRACTION

\begin{tabular}{ccccccccc}
\hline No. & $\mathrm{A}$ & $\mathrm{B}$ & $\mathrm{C}$ & $\mathrm{D}$ & $\mathrm{E}$ & $\mathrm{F}$ & $\mathrm{G}$ & Pectin yield (\%) \\
\hline 1 & $1(150)$ & $1(40)$ & $1(8)$ & $1(55)$ & $1(3.5)$ & $1(45)$ & $1(0.7)$ & 17.83 \\
2 & 1 & $2(50)$ & $2(10)$ & $2(60)$ & $2(4.0)$ & $2 .(50)$ & $2(0.9)$ & 20.43 \\
3 & 1 & $3(60)$ & $3(12)$ & $3(65)$ & $3(4.5)$ & $3(55)$ & $3(1.1)$ & 18.10 \\
4 & $2(200)$ & 1 & 1 & 2 & 2 & 3 & 3 & 18.65 \\
5 & 2 & 2 & 2 & 3 & 3 & 1 & 1 & 19.53 \\
6 & 2 & 3 & 3 & 1 & 1 & 2 & 2 & 19.90 \\
7 & $3(250)$ & 1 & 2 & 1 & 3 & 2 & 3 & 20.25 \\
8 & 3 & 2 & 3 & 2 & 1 & 3 & 1 & 20.33 \\
9 & 3 & 3 & 1 & 3 & 2 & 1 & 2 & 18.64 \\
10 & 1 & 1 & 3 & 3 & 2 & 2 & 1 & 18.98 \\
11 & 1 & 2 & 1 & 1 & 3 & 3 & 2 & 20.12 \\
12 & 1 & 3 & 2 & 2 & 1 & 1 & 3 & 19.44 \\
13 & 2 & 1 & 2 & 3 & 1 & 3 & 2 & 20.87 \\
14 & 2 & 2 & 3 & 1 & 2 & 1 & 3 & 20.88 \\
15 & 2 & 3 & 1 & 2 & 3 & 2 & 1 & 21.03 \\
16 & 3 & 1 & 3 & 2 & 3 & 1 & 2 & 20.98 \\
17 & 3 & 2 & 1 & 3 & 1 & 2 & 3 & 21.02 \\
18 & 3 & 3 & 2 & 1 & 2 & 3 & 1 & 20.88 \\
$\mathrm{~K}_{1}$ & 19.15 & 19.59 & 19.55 & 19.98 & 19.90 & 19.55 & 19.76 & - \\
$\mathrm{K}_{2}$ & 20.14 & 20.39 & 20.23 & 20.14 & 19.74 & 20.27 & 20.16 & - \\
$\mathrm{K}_{3}$ & 20.35 & 19.67 & 19.86 & 19.52 & 20.00 & 19.83 & 19.72 & - \\
$\mathrm{R}_{\mathrm{i}}$ & $1.20(1)$ & $0.8(2)$ & $0.68(4)$ & $0.62(5)$ & $0.26(7)$ & $0.72(3)$ & $0.44(6)$ & - \\
\hline
\end{tabular}


stretching vibration, indicating the presence of a large number of -OH within the pectin molecule or among pectin molecules. The appearance of the peak near $3450 \mathrm{~cm}^{-1}$ indicated the presence of obvious intermolecular hydrogen bond. In addition, the absorption peak at $2942 \mathrm{~cm}^{-1}$ was attributed to the $\mathrm{C}-\mathrm{H}$ stretching vibration of carbohydrates; the peak at $1750 \mathrm{~cm}^{-1}$ corresponded to the $\mathrm{C}=\mathrm{O}$ stretching vibration, indicating the presence of an acetyl group in pectin. The absorption peak at $1620 \mathrm{~cm}^{-1}$ corresponded to the $\mathrm{C}=\mathrm{O}$ stretching vibration within $-\mathrm{CHO}$; the peaks at 1445 and $1414 \mathrm{~cm}^{-1}$ was attributed to the C-O-C plane bending vibration and the peaks at 1340 and 1360 $\mathrm{cm}^{-1}$ was ascribed to the $\mathrm{O}-\mathrm{H}$ bending vibration. The weak band at $1150-1060 \mathrm{~cm}^{-1}$ was attributed to the asymmetric C-O-C stretching vibration, indicating the presence of $-\mathrm{O}-\mathrm{CH}_{3}$; the absorption peaks at 1103 and $1015 \mathrm{~cm}^{-1}$ and at $1200-1000$ $\mathrm{cm}^{-1}$ were ascribed to the ether and hydroxyl absorption peaks of the pyranose sugar ring; and the absorption peak near 910 $\mathrm{cm}^{-1}$ was attributed to the characteristic D-pyranose glucose absorption peak. The absence of twin peaks at $3500-3300 \mathrm{~cm}^{-1}$ $\left(-\mathrm{NH}_{2}\right)$ indicated the absence of protein.

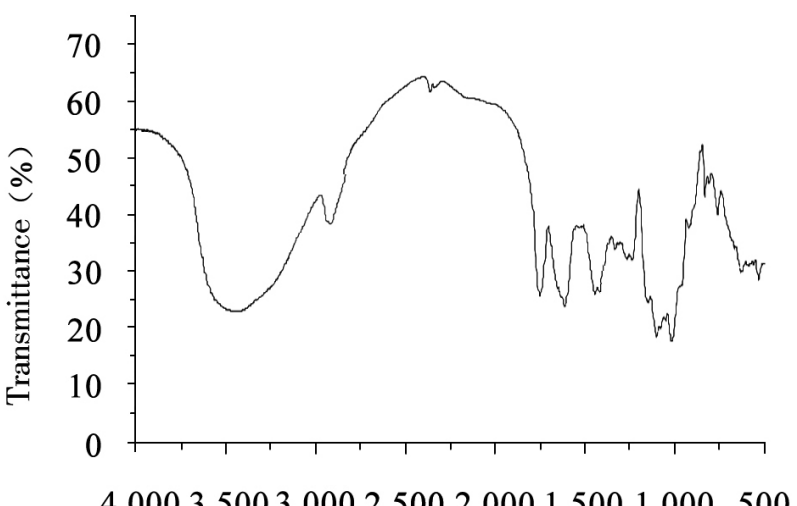

\footnotetext{
Wavenumber $\left(\mathrm{cm}^{-1}\right)$

Fig. 5. FTIR spectrum of pectin
}

Component analysis: The drying weight decreased and the contents of sulphur dioxide, acid insoluble ash, total galacturonic acid and heavy metal lead all met the GB 255332010 requirements. The total galacturonic acid content reached $66 \%$, which was higher than the provisions in GB 255332010. The indicators are shown in Table-2.

\section{TABLE-2}

PHYSIOCHEMICAL PERFORMANCE INDEX OF PECTIN

\begin{tabular}{lcc}
\hline Pectin properties and composition & Test results & GB 25533-2010 \\
\hline Colour and luster & Beige & Pale yellow \\
Texture & Powder & Powder \\
Weight decrease $(\mathrm{w} / \%)$ & 4.82 & $\leq 12$ \\
Sulfur dioxide $(\mathrm{mg} / \mathrm{kg})$ & 22.33 & $\leq 50$ \\
Acid insoluble ash $(\mathrm{w} / \%)$ & 0.098 & $\leq 1$ \\
Total galacturonic acid $(\mathrm{w} / \%)$ & 66.21 & $\geq 65$ \\
Heavy metal lead $(\mathrm{mg} / \mathrm{kg})$ & 0.225 & $\leq 5$ \\
\hline
\end{tabular}

\section{Conclusion}

Microwave-assisted compound enzyme method was used to extract orange peel pectin. The conjunction of two separate extraction methods prevented high temperature-induced damage on the structure of pectin compounds, which can improve pectin yield and purity. The optimal conditions were $250 \mathrm{~W}$ microwave power, $50{ }^{\circ} \mathrm{C}$ microwave heating temperature, 10 min microwave processing time, $1 \mathrm{~h}$ single extraction time, 4.5 buffer $\mathrm{pH}, 50{ }^{\circ} \mathrm{C}$ enzyme extraction temperature, 0.9 $\%$ enzymatic dosage and three additional experiments using these optimal conditions. Under these conditions, the average extraction yield of the orange peel pectin was $22.12 \%$, which was $8.71 \%$ higher than the pectin extraction yield using the conventional water bath method under similar process conditions. Moreover, the pectin had high purity and was protein-free.

\section{ACKNOWLEDGEMENTS}

This work received financial aid from the Science and Technology Department of Hunan Province (Serial No. 2010GK3118).

\section{REFERENCES}

1. H. Liu, D.S. Zhu and X.M. Xu, Food Sci., 3, 81 (2009).

2. P.B. Sutar, R.K. Mishra, K. Pal and A.K. Banthia, J. Mater. Sci. Mater. Med., 19, 2247 (2008).

3. Z.H. Liang, X.H.Liu and J.M. Li, J. Nanchang Univ., 6 (2011).

4. T. Nakagawa, T. Miyaji, H. Yurimoto, Y. Sakai, N. Kato and N. Tomizuka, Appl. Environ. Microbiol., 66, 4253 (2000).

5. M.H.G. Canteri, A.P. Scheer, G. Wosiacki, C. Ginies, M. Reich and C.M.C.G. Renard, J. Polym. Enviorn., 18, 593 (2010).

6. T. Sakai, T. Sakamoto, J. Hallaert and E.J. Vandamme, Adv. Appl. Microbiol., 39, 213 (1993).

7. W.G.T. Willats, J.P. Knox and J.D. Mikkelsen, Trends Food Sci. Technol., 17, 97 (2006).

8. G.Y. Zhao, H.J. Diao and L.Q. Jing, Food Machinery, 6, 47 (2011).

9. G.E. Anthon and D.M. Barrett, Food Chem., 110, 239 (2008).

10. X.T. Yue, Food Res. Dev., 4, 101 (2011).

11. A.R. Shen, Z.M. Tan and C.Z. Li, China Oils Fats, 3, 6 (2010).

12. X.C. Yu, D.L. Sun and X.S. Li, Asian J. Chem., 24, 1743 (2012).

13. W. Feng, B. Gao and M.Y. Li, J. Anhui Agric. Sci., 33, 20577 (2011). 